\title{
Stimulus-reinforcer interactions in Pavlovian conditioning of pigeons: Implications for selective associations
}

\author{
KIMRON L. SHAPIRO, W. J. JACOBS, and VINCENT M. LoLORDO \\ Dalhousie University, Halifax, Nova Scotia, Canada B3H 4JI
}

In a Pavlovian procedure, groups of pigeons were presented with a compound auditoryvisual stimulus that terminated with either response-independent electric shock or food. In a subsequent test, the tone CS was dominant in aversive conditioning, reliably eliciting conditioned head raising and prancing. The red light CS was dominant in appetitive conditioning, reliably eliciting pecking. This result was replicated in a second experiment, in which trials were widely spaced. Four additional groups of pigeons received pairings of the separate element CSs with the USs. Red light, but not tone, was an effective CS in appetitive conditioning, whereas tone, but not red light, was effective in aversive conditioning. There was no discriminative responding in zero-contingency control groups. Several theoretical accounts of these data are discussed.

Recently, there have been several demonstrations that an animal's performance in a conditioning experiment may be markedly affected by the experimenter's choice of particular combinations of conditioned or discriminative stimuli and reinforcers. Certain combinations of stimuli and reinforcers may fail to produce changes in behavior, whereas other combinations from the same set of elements result in marked changes in performance (e.g., Foree \& LoLordo, 1973; Garcia \& Koelling, 1966; Jacobs \& LoLordo, 1977, 1980). Such an outcome will be called a stimulus-reinforcer interaction. Demonstrations of stimulus-reinforcer interactions have aroused interest because they suggest that organisms' abilities to associate stimuli and reinforcers are somehow constrained and thus that there may be strong constraints on the generality of the laws of learning. A constraintson-learning account of stimulus-reinforcer interactions suggests that there are selective associations between stimuli and reinforcers, that is, that connections between certain CSs and USs may be formed very easily, whereas connections between other CSs and USs from the same set may not be formed at all, or only with great difficulty.

Two basic experimental designs have been used in demonstrations of such stimulus-reinforcer inter-

This research was supported by Grant A0283 from the Natural Sciences and Engineering Research Council to V.M.L. Some of the research reported here was described by K.S. at the 1977 meeting of the Eastern Psychological Association. The authors are indebted to Jeffrey Willner for his comments on an earlier draft of this report and to Nancy Beattie for typing the manuscript. Requests for reprints should be sent to Kimron L. Shapiro, Department of Man-Environment Relations, S-126 Henderson Human Development Building, Pennsylvania State University, University Park, Pennsylvania 16802 . actions (LoLordo, 1979). In the single-cue design, four groups of organisms receive the factorial combinations of two CSs and two USs. If acquisition of a CR occurs more rapidly with CS1 than with CS2 when US1 is the reinforcer, but the reverse is true when US2 is the reinforcer, then a stimulus-reinforcer interaction has been observed. Such interactions can also be demonstrated in a compound-cue design, in which two groups of organisms receive a simultaneous compound of the two CSs during conditioning, but the compound CS is paired with different USs in the two groups. The response to the separate elements of the compound is assessed in a series of test trials following conditioning. If there is more test responding to CS1 than to CS2 when US1 is the reinforcer, but the reverse is true when US2 is the reinforcer, again a stimulus-reinforcer interaction has occurred. The occurrence of a stimulus-reinforcer interaction cannot be attributed solely to a difference between the CSs or solely to a difference between the USs, but must reflect some selective effect on learning or performance (Schwartz, 1974).

In one experiment using the compound-cue design, Foree and LoLordo (1973) trained groups of pigeons to press a treadle in the presence of an auditoryvisual compound stimulus to obtain grain or to avoid electric shock. Responding in the absence of the compound stimulus postponed its next occurrence. When the birds were responding on at least $75 \%$ of the compound trials, but responding infrequently between trials, the degree to which the compound and each element controlled treadle pressing was determined. The compound stimulus exerted strong control over treadle pressing in both groups. In the appetitive group, there was strong visual dominance; red light strongly controlled treadle pressing, but few responses 
occurred during the tone. On the other hand, in the shock-avoidance group, the tone controlled more responding than did the red light; that is, there was auditory dominance.

Foree and LoLordo (1973) did not demonstrate that the stimulus-reinforcer interaction effect they observed reflected selective associations rather than some selective, nonassociative effect, for example, selective sensitization (see LoLordo, 1979, for a discussion of this issue). The first step in demonstrating that selective associations were formed would be to demonstrate that the responses that the compound stimuli came to control were associative, that is, depended upon the positive contingency between $\mathrm{CS}$ and US. This step is easier to take in a classical conditioning experiment than in a discriminated operant procedure like that used by Foree and LoLordo, primarily because, in the former, the experimenter has control over the number and temporal pattern of CSs and USs presented to the organism. Consequently, groups that receive the same number of CSs and USs as the experimental groups, but with a zero-contingency between CS and US, can be used as controls for nonassociative effects.

In the present context, the Pavlovian conditioning procedure has the added advantage of allowing the experimenter to equate the shock density received by birds in an aversive conditioning procedure with the density of food reinforcement received by the pigeons in an appetitive procedure. In contrast, in Foree and LoLordo (1973) the probability of food increased as acquisition progressed, whereas the probability of shock decreased.

For these reasons, a Pavlovian conditioning procedure was used in the present experiments. We were able to determine whether the pattern of responses that emerges when no response is required of the bird yields the same stimulus-reinforcer interaction observed by Foree and LoLordo, who analyzed only differences in the probability of occurrence of a single response, treadle pressing. In the present studies, birds were observed visually, so that any change in behavior that occurred in the presence of the CS could be analyzed.

The compound-cue design was used in Experiment 1; two groups of pigeons received pairings of the compound CS and a US, either food or shock. In the second experiment, additional groups received uncorrelated presentations of the compound CS and a US, and thus were controls for nonassociative effects of the procedure. Experiment 2 also included the single-cue design; four groups received pairings-of the individual stimulus elements that constituted the compound with a US.

\section{EXPERIMENT 1}

In Experiment 1, three pigeons received repeated presentations of a compound CS, consisting of onset of a tone and illumination of red houselights, followed by response-independent grain, the US. Three other birds received pairings of the same compound CS and electric shock. Following conditioning, responses to the compound and the separate elements were assessed.

\section{Method}

\section{Subjects}

Subjects were six experimentally naive male White Carneaux pigeons, housed in individual cages of a colony room. All pigeons were maintained at $80 \%$ of their free-feeding weights, had constant access to water, and were maintained on a 12 -h light $/ 12-\mathrm{h}$ dark cycle. On the day prior to the first experimental session, stainless steel wire electrodes were implanted around the pubis bones of each bird. The electrodes were connected to a double banana plug, which was attached to a leather harness worn at all times (Azrin, 1959; Coughlin, 1970).

\section{Apparatus}

Sessions were conducted in a $42 \mathrm{~cm}$ long $\times 29 \mathrm{~cm}$ wide $\times 36 \mathrm{~cm}$ high chamber located in a darkened room. A $6 \times 5 \mathrm{~cm}$ food magazine was centered on the black Plexiglas end wall, $7 \mathrm{~cm}$ above the cardboard-backed wire grid floor. A darkened pigeon key was located above the magazine. A speaker was mounted on the back wall, at the upper corner adjacent to the food magazine. The tone stimulus was $440 \mathrm{~Hz}$ and raised the sound level from 53 to $71 \mathrm{~dB}$ (Scale C of a sound-level meter). The visual CSs came from light bulbs mounted above a translucent white Plexiglas ceiling. Illumination of four red 120-VAC 7-W Christmas-tree bulbs served as the red-light stimulus, and illumination of two similar white bulbs served as the white-light (intertrial) stimulus. The front wall of the chamber, which was transparent Plexiglas, was hinged and allowed access to the chamber.

Electric shock $(60-\mathrm{Hz}, 110-\mathrm{V}$ alternating current passed through a variable transformer and a $10-\mathrm{k} \Omega$ resistor) was transmitted via the cables attached to a swivel mounted in the ceiling of the box. A double banana plug on the swivel cable was plugged into the double banana socket on the bird's harness before each session. This arrangement allowed the birds to move freely.

Masking noise was provided by the ventilation fan mounted on the chamber and by white noise in the experimental room. A video camera stood outside the chamber, facing the transparent front wall. A video monitor, a video tape recorder, and all programming equipment were located in an adjacent room. A microphone mounted above the white Plexiglas chamber and connected through an amplifier to a speaker in the control room allowed the observers to judge tone onset.

\section{Procedure}

Conditioning. All pigeons received $30-$ min conditioning sessions on 5 consecutive days. Each Pavlovian conditioning trial consisted of a 5 -sec presentation of the auditory-visual compound conditioned stimulus followed by the US. The compound stimulus consisted of the simultaneous onset of the red houselight and a $440-\mathrm{Hz}$ tone. For three birds, the US was a brief, $52-\mathrm{msec}, 45-\mathrm{V}$ electric shock; for the other three birds, it was $3 \mathrm{sec}$ access to mixed grain. The food magazine was illuminated whenever grain was available. A $15-\mathrm{sec}$ interval, during which the white houselight was illuminated, separated the termination of one CS from the onset of the next. Thus, there were 90 conditioning trials per session.

Birds in the appetitive conditioning group did not receive magazine training prior to the conditioning sessions, but at the start of the first conditioning session the illuminated grain magazine was elevated, and the 30 -min trial sequence started only after the birds began eating from the grain magazine. 
During conditioning, several experimenters observed the development of various conditioned responses, in order to construct a set of behavioral categories that could be used during the subsequent test.

Testing. On the day following the last day of conditioning, the pigeons received 20 presentations of the compound CS followed by the US, and then received 7 test presentations each of red light, tone, and no signal (blank trials) randomly interspersed among 49 presentations of the compound CS. Reinforcement occurred on all but the blank trials, which were included to assess the possibility of conditioning to temporal cues. Stimulus durations and the intertrial interval were like those used in conditioning.

Three observers, including one who was not told about the purpose of the experiment, recorded whether certain predesignated behaviors occurred on each trial. Performance during test sessions was also recorded on videotape.

\section{Results}

\section{Acquisition}

All pigeons began responding to the $\mathrm{CS}$ in a distinctive fashion by the fifth conditioning session. Conditioned behavior was highly stereotyped for all birds within a given reinforcement condition. In the presence of the CS, all birds in the appetitive condition typically pecked in or around the food hopper. On most of the trials, pecking was initiated when the CS occurred. Occasionally, pecking was already occurring but increased in frequency when the CS was presented. Pigeons in the aversive condition typically were facing the transparent front wall and then raised their heads and pranced vigorously in response to the CS. "Head raising," which typically occurred while the bird was otherwise motionless, refers to lifting the head a few centimeters above its previous position. "Prancing" refers to rapid side-to-side movements, during which the pigeon lifts its feet higher than in normal walking. The CR was quite similar to some components of the response to shock, although the latter tended to be more vigorous. Head raising and prancing occurred infrequently, and with less vigor, between trials.

\section{Test: Appetitive Condition}

In the test session, the three birds in the appetitive condition were observed to peck in or around the food hopper on virtually all presentations of the compound CS. The three observers' judgments of the occurrence or nonoccurrence of this behavior were in agreement on $84 \%-96 \%$ of the trials. The left panel of Figure 1 illustrates, for each bird, the percentage of trials on which a peck CR occurred for each of the four types of test trials. The percentages shown are means for three observers. Each bird pecked on virtually all presentations of the visual CS, as well as on presentations of the compound. In contrast, the birds rarely pecked during presentations of the auditory CS or on "blank" trials.

Birds 8628 and 8725 made a second characteristic

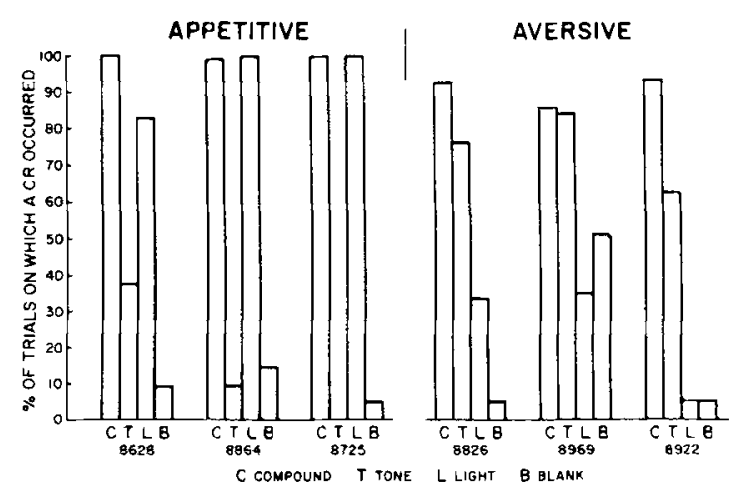

Figure 1. Left panel ilustrates, for each bird in the appetitive condition of Experiment 1, the percentage of trials on which a peck CR occurred during each of the four test stimuli. Right panel illustrates, for each pigeon in the aversive condition, the percentage of trials on which head raising occurred during each of the four test stimuli.

response on virtually all presentations of the compound CS. They crouched, so that their bodies were lowered, with the horizontal axis parallel to the floor. This response was also judged reliably $(>92.9 \%$ agreement). For Bird 8725 , this response was perfectly correlated with pecking. For Bird 8628, the correlation between body lowering and pecking was broken only on presentations of the tone. This bird lowered its body on $62 \%$ of the tone trials, as opposed to $100 \%$ of compound and red-light trials and only $14 \%$ of blank trials.

\section{Test: Aversive Condition}

All three birds in the aversive conditioning group were observed to raise their heads and then prance on most of the presentations of the compound CS. Observers' judgments of these behaviors were in agreement on $89 \%-91 \%$ of the trials. Whenever it raised its head, Bird 8826 then turned its head from side to side repeatedly. Bird 8922 made repeated up-and-down head-bobbing motions after raising its head. The right panel of Figure 1 illustrates for each bird the mean percentage of trials on which head raising occurred for each of the four types of test trials. All birds raised their heads on a large proportion of the compound trials. Moreover, they made this response on many more tone than red-light trials. Little head raising was observed on blank trials except in Bird 8969 , which raised its head on roughly $50 \%$ of the blank trials.

Bird 8969 pranced after every head-raising $C R$, whereas Birds 8826 and 8922 pranced on most of the trials on which they raised their heads $(77 \%$ and $89 \%$ of the compound trials, $37 \%$ and $52 \%$ of the tone trials, $14 \%$ and $2 \%$ of the red-light trials, and $3 \%$ and $7 \%$ of the blank trials for Birds 8826 and 8922 , respectively).

Two birds made at least one other response, in 
addition to head movements and prancing, on most of the compound trials. Birds 8826 and 8969 were observed to flap their wings, generally after beginning to prance, on $69 \%$ and $74 \%$ of the compound trials, respectively. The observers' judgments of wing flapping were in agreement on $74 \%$ and $86 \%$ of the trials for the two birds. Bird 8826 rarely flapped its wings except on compound trials. In contrast, Bird 8969 flapped its wings on $67 \%$ of tone trials but on only $14 \%$ and $19 \%$ of red-light and blank trials, respectively.

\section{Discussion}

Analysis of responses to the test presentations of the stimuli reveals that there was strong visual dominance in the appetitive condition. Both body lowering and pecking in or around the hopper revealed this visual dominance, and the effect was weak only in the case of body lowering for Bird 8628. Except in this case, conditioned responses rarely occurred during the auditory stimulus or on blank trials. On the other hand, there was clear auditory dominance in the aversive condition. Auditory dominance was strong for raising and bobbing the head and prancing for Bird 8922. It was also strong for head raising, prancing, and wing flapping for Bird 8969, although that bird pranced on many blank trials, suggesting that its responding may have been controlled in part by temporal cues. For these two birds, there was no indication that any response had been conditioned to the red light, since responding to light never exceeded responding to blank trials. For Bird 8826, raising and turning the head was the most probable response. The auditory CS evoked more conditioned responding than the visual CS, which in turn evoked more responding than blank trials. Prancing, a less probable response, revealed only weak conditioning to the tone, and no conditioning to the light. Finally, there was even less wing flapping, and no firm evidence that this response was conditioned to either element.

The joint outcome of visual dominance in the appetitive procedure and auditory dominance in the aversive situation replicates the pattern of results obtained by Foree and LoLordo (1973), who compared stimulus control of treadle pressing for food with control of treadle pressing to avoid shock. The highly similar outcomes of the two studies suggest that the response-reinforcer contingencies used by Foree and LoLordo are not a necessary condition of the observed stimulus-reinforcer interaction. For example, the present data suggest that the auditory dominance observed in Foree and LoLordo's avoidance procedure probably resulted from pairings of the compound stimulus and shock early in training, rather than from the occurrence of avoidance responses in the presence of the compound. Furthermore, the stimulus-reinforcer interaction observed by Foree and LoLordo cannot be attributed to the gradual reduction in the number of shocks per session coupled with the increase in the number of food reinforcements per session that resulted from the responsedependent procedures they used.

There was virtually no responding to the nondominant stimuli following compound conditioning in the present experiment. Thus, there was little evidence to suggest that these stimuli were associated with the USs.

\section{EXPERIMENT 2}

In Experiment 2, separate groups of pigeons received repeated pairings of the compound, the red light, or the tone CS with food or electric shock. The use of the single-cue design in this experiment allows us to determine whether the stimulus-reinforcer interaction observed in compound conditioning in Experiment 1 depends upon some process that arises only when a compound CS is used, for example, selective attention (Sutherland \& Mackintosh, 1971). If the same stimulus-reinforcer interaction were observed in the single-cue design, then any adequate account of this interaction would have to be couched in terms of the relative effectiveness of the various CS-US combinations in generating conditioning.

Additional groups of pigeons received random presentations of the compound, red light, or tone CS and a US, either grain or electric shock. Inclusion of these zero-contingency control groups enables us to ascertain whether the responses to the CS that developed in the experimental groups resulted from the positive contingency between CS and US that existed for those groups. That is, if the same stimulus-reinforcer interaction were observed in the zero-contingency and positive-contingency groups, then it could not be concluded that the effect is associative.

\section{Method}

\section{Subjects}

Subjects were 36 experimentally naive male White Carneaux pigeons, which were housed and maintained as in Experiment 1. Shock electrodes were implanted in each pigeon as in Experiment 1.
Apparatus
A second, identical chamber was added to the one used in Experiment 1.

\begin{abstract}
Procedure
Conditioning. Eighteen birds received a 52-msec, 45-V ac electric shock as the US, whereas the other 18 received 3 sec access to mixed grain. Within each US condition, nine birds received repeated CS-US pairings: Three brids received the compound CS of Experiment 1, three received the red light CS, and three, the tone CS. In order to minimize the possibility of intertrial responding and reduce the likelihood of habituation to the shock US, conditioning trials were separated by an average interval of I $50 \mathrm{sec}$ (minimum interval $=18 \mathrm{sec}$ ). There were 12 conditioning trials per session. A variable intertrial interval was used to minimize
\end{abstract}


the chance of temporal conditioning, even though temporal conditioning did not play a major role in the first experiment. Nine additional pigeons in each US condition received random presentations of CS and US: Three received the compound CS, three, the red light, and three, the tone. The number of CSs and USs per session was matched with the experimental groups, but there was no contingency between the two events; that is, they were presented on independent variable-time 150 -sec schedules. Each bird received conditioning sessions until it made at least $75 \%$ CRs on two consecutive sessions or until 15 sessions had elapsed.

During conditioning, an observer recorded the development of various conditioned responses on a trial-by-trial basis, using the hehavioral categories developed during Experiment 1. Birds in all groups were observed on every trial.

Testing. On the 2 days following the last day of conditioning, pigeons that had received pairing of the compound CS and a US were tested, as their counterparts had been in Experiment 1. In each test session there were four presentations of the compound CS, four of the red light, and four of the tone. No more than two trials of a given type could occur consecutively. Reinforcement occurred on all trials, and the stimulus durations and the intertrial interval were like those used in conditioning.

\section{Results}

\section{Appetitive Condition}

Acquisition. The three birds that received pairings of compound CS and food quickly began to peck in or around the hopper during the CS, as did their counterparts in the first experiment. The top panel of Figure 2 illustrates, for each bird, the number of sessions (including the criterial sessions) to a criterion of two consecutive sessions with at least $75 \% \mathrm{CRs}$. None of the birds that received a zero-contingency between the compound CS and food reached this criterion. Moreover, percent CRs showed no trend across the 15 sessions, and the highest percent CRs for any bird in any session was $25 \%$.

The three birds that received pairings of the redlight CS and food also began to peck in or around the hopper during the CS. One of the birds, 2417, pecked the hopper at a low rate during the pre-CS period, and the CR for this bird was a marked increase in the rate of pecking when the CS came on. The bottom panel of Figure 2 illustrates the number of sessions to criterion for these birds. As in the case of the compound-food group, conditioning occurred rapidly. None of the birds that received a zerocontingency between the red-light CS and food reached criterion. Again, percent CRs showed no trend across sessions, and no pigeon made more than $25 \%$ CRs in any session.

In contrast with birds that received pairings of redlight or compound CS with food, birds that received tone-food pairings did not acquire a conditioned response (see the middle panel of Figure 2). Moreover, only of the three birds responded at all; it pecked during the CS on roughly a third of the trials on Sessions $2-4$, but then this behavior ceased. Generally, birds that received a zero-contingency between tone and food responded like birds in the other zero-

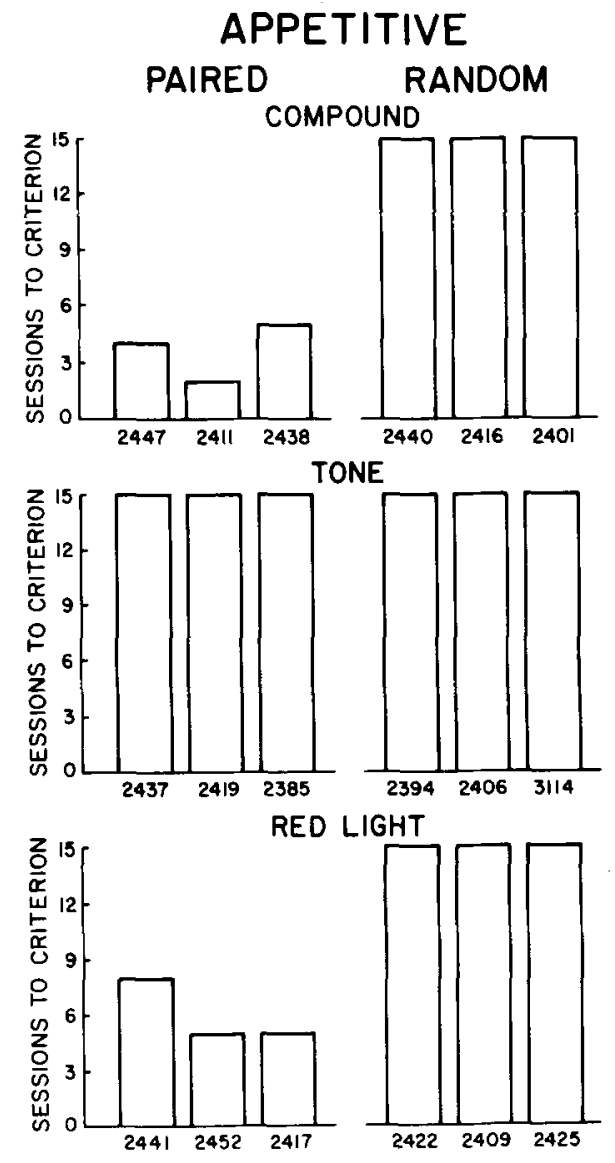

Figure 2. Top panel illustrates, for each bird in the appetitive, compound stimulus condition of Experiment 2, the number of sessions (including the criterial sessions) to a criterion of two consecutive sessions with at least $75 \%$ CRs. The middle and bottom panels illustrate comparable data for the groups that received tone and red-light CSs, respectively.

contingency groups. None reached criterion, and none ever pecked on more than a third of the trials in a session. There was no difference between birds that received tone-food pairings and those that received a zero-contingency between the two events. Thus, there was no evidence that repeated pairings of tone and food resulted in the formation of an association.

Testing. The left-hand panel of Figure 3 shows that, during the two test sessions following conditioning, the three birds that had received pairings of the compound CS and food responded on virtually all compound and red-light trials, but responded infrequently on tone trials. The CR topographies during testing were the same as those observed during acquisition.

\section{Aversive Condition}

Acquisition. The three birds that received pairings of the compound CS and shock generally behaved like their counterparts in Experiment 1. All three birds began to raise their heads during the CS, and, 


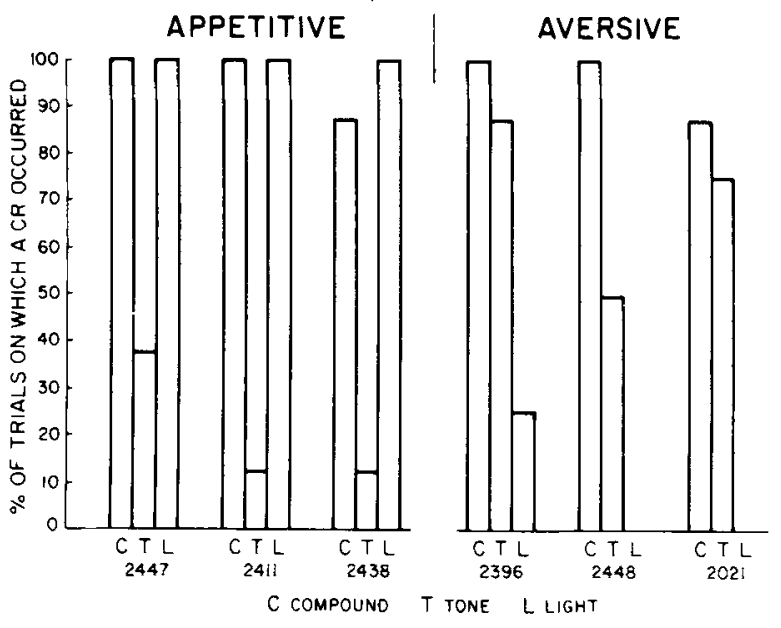

Figure 3. Left panel illustrates, for each bird in the appetitive, compound CS+ group of Experiment 2, the percentage of trials on which a peck CR occurred during each of the three test stimuli. Right panel illustrates, for each bird in the aversive, compound CS + group, the percentage of trials on which head raising occurred during each of the three test stimuli.

on most of the trials, prancing followed head raising. The top panel of Figure 4 illustrates, for each bird in this group, the number of sessions to a criterion of two consecutive sessions with at least $75 \%$ CRs. For Birds 2396 and 2448, prancing always accompanied head raising; thus, both responses met the criterion. For Bird 2021, head raising was the response that met criterion; prancing accompanied head raising on roughly $70 \%$ of the trials.

None of the birds that received a zero-contingency between the compound $\mathrm{CS}$ and electric shock reached the acquisition criterion. One of the birds in this group (2931) rarely responded. A second bird (2451) raised its head and pranced on as many as $58 \%$ of the trials in a session (mean $=31 \%$, with no trend across sessions). The third bird (2414) tended to raise its head (and, less frequently, to prance) both prior to and during the CS on roughly one-third of the trials. It also responded during the CS on a few trials on which it had not responded prior to the CS.

As in the case of the compound-shock group, conditioning occurred rapidly for the three birds that received pairings of tone and shock. All three birds began to raise their heads during the $\mathrm{CS}$, and, for two of the three birds $(2435,3788)$, prancing accompanied head raising. For the third bird (2382), prancing accompanied head raising on roughly half the trials. The middle panel of Figure 4 illustrates, for each bird in this group, the number of sessions to criterion. For Bird 2382, head raising was the response that met criterion; for the other two birds, both responses met criterion.

None of the birds that received a zero-contingency between tone and shock reached the criterion. None of these birds ever made more than 17\% head-raising or prancing CRs in a session, and they never responded between trials.

In contrast with the birds that received compoundshock or tone-shock pairings, none of the birds that received red light-shock pairings reached the acquisition criterion (bottom panel, Figure 4). Moreover, only one of the three birds (2436) ever made more than $8 \%$ CRs in a session. This bird raised its head and pranced on $8 \%$ of the trials or less until Sessions 13-15, when it had 17\%, 42\%, and 58\% CRs. Because there appeared to be a trend in the data, two additional sessions were conducted. The bird made $25 \%$ and $17 \%$ CRs on these sessions.

None of the birds that received a zero-contingency between red light and shock reached the acquisition (Figure 4). After the first few sessions, Bird 2400 raised its head and pranced both before and during most CS presentations. Responding declined on session 7, and rarely occurred thereafter. Bird 2454 rarely raised its head or pranced during the CS, and, on most of those occasions when it did respond, the response also had occurred prior to the CS. Bird 2443 raised its head
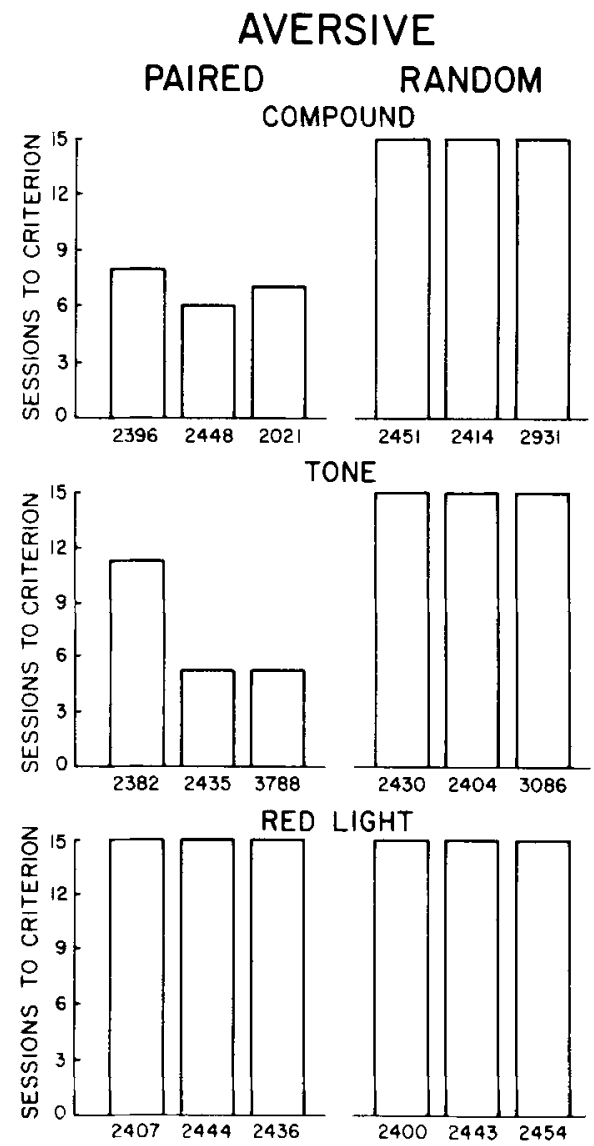

Figure 4. Top panel illustrates, for each bird in the aversive, compound stimulus condition of Experiment 2, the number of sessions (including criterial sessions) to a criterion of two consecutive sessions with at least $75 \%$ CRs. The middle and bottom panels illustrate comparable data for the groups that received tone and red-light CSs, respectively. 
and pranced on an average of $12 \%$ of the trials, and there was no trend in the data.

Testing. The right-hand panel of Figure 3 illustrates responding during the two test sessions that followed conditioning by birds that had received compoundshock pairings. Each bird responded on virtually all compound trials and on somewhat fewer tone trials. Conditioned response topographies were like those observed during acquisition. Two birds failed to respond on red-light trials, and the third responded infrequently.

\section{Discussion}

The test performances of the pigeons that had received pairings of the compound CS and a US were generally like the performances of the birds in Experiment 1 in all important respects. The visual stimulus was dominant when the US was food, but the auditory stimulus was dominant when electric shock was the US.

The single-cue design was included in this experiment to assess the possibility that the dominance effects observed following compound conditioning are the result of some process that emerges in compound conditioning procedures and do not simply reflect the relative conditionability of the various cues. The results of the single-element conditioning treatments suggest that the dominance effects observed with electric shock and food do reflect the relative conditionability of tone and red light.

Consider the groups that received food reinforcement. The three birds that received pairings of red light and food acquired a CR, pecking, in five to eight sessions, whereas none of the three birds that received pairings of tone and food responded discriminatively to tone in 15 sessions. These data are consonant with the test data from birds that had received compound conditioning in Experiments 1 and 2, and are in accord with the suggestion that the tone was not associated with food.

Now consider the groups that received the electric shock US. The three birds that received tone-shock pairings during conditioning acquired a $C R$, head raising and prancing, in 5-11 sessions, whereas the three birds that received red light-shock pairings failed to acquire a CR in 15 sessions. These data, too, are consonant with test data from birds that had received compound conditioning, and are in accord with the suggestion that the red light was not associated with shock.

Single-cue experiments in which auditory or diffuse visual CSs have been paired with food have been conducted in several other laboratories. In an unpublished PhD thesis, Newlin (1974) presented pigeons with repeated pairings of $10-\mathrm{sec}$ illumination of red houselights followed by access to grain. By the end of the first 60-trial session, pecking at or near the food hopper was reliably elicited by the CS. On the other hand, Leyland and Mackintosh (1978) observed no pecking during illumination of a blue houselight when that CS repeatedly preceded access to grain. Perhaps the more extensive magazine training used by Leyland and Mackintosh was responsible for the failure of pecking to develop in their experiment (see Tomie, 1980 , for a discussion of this issue), but such a USpreexposure effect cannot be construed as a failure of a blue light-food association, because Leyland and Mackintosh found that blue light subsequently blocked conditioning to an added keylight stimulus.

Leyland and Mackintosh also administered repeated pairings of an auditory CS and food to pigeons. They observed no pecking during the auditory CS. Similar results were obtained by Rashotte, Griffin, and Sisk (1977) and by Winokur and Boe (Note 1). Apparently, the failure to peck observed by Leyland and Mackintosh and by Rashotte et al. did not reflect a failure of association, since the former found that the tone subsequently blocked conditioning to an added keylight, and the latter found that the tone subsequently was an effective first-order stimulus in a second-order conditioning procedure.

Other investigators have observed conditioned responses during auditory signals for food. Wasserman (1972) observed head turning and bobbing in response to a train of clicks that had been paired with access to grain. Farthing (1971) observed orientation toward, and some pecking at, the grain hopper during an auditory $\mathrm{CS}+$, and a smaller amount of orientation toward the speaker itself. Newlin (1974) observed consistent pecking at or around the hopper during an auditory $\mathrm{CS}+$ in all seven birds that received tonefood pairings, although pecking developed more slowly than in the case of a red light paired with food. The basis of these discrepant outcomes is unclear; however, the last two studies employed a longer CS-US interval (and CS duration) than the studies in which there was no pecking. Perhaps there was an initial startle response to the tone in these studies, and a longer CS-US interval permitted this startle to dissipate and pecking to emerge.

Thus far, the discussion has assumed that test responding to the CS was conditioned, that is, reflected an association between CS and US that depended on the positive contingency between CS and US. The data from the zero-contingency groups of Experiment 2 bear on this assumption. Pigeons that received random and independent presentations of a CS and a US failed to acquire a conditioned response. This finding indicates that the positive contingency between CS and US in the experimental groups is a necessary condition for the development of discriminative responding to the $\mathrm{CS}$, that is, that the effects observed in the experimental groups were associative. 


\section{GENERAL DISCUSSION}

Demonstrations of stimulus-reinforcer interactions in classical and instrumental conditioning have aroused interest largely because they suggest that selective associations between stimuli and reinforcers sometimes occur. Selective association implies that connections between certain antecedent and consequent events (CS1-US1, CS2-US2) within a set of events (CS1, CS2, US1, US2) may be formed very easily, whereas connections between other antecedents and consequents (CS1-US2, CS2-US1) within the set may not be formed at all, or only with great difficulty (LoLordo, 1979). In Rescorla and Wagner's (1972) model of Pavlovian conditioning, two separate learning-rate parameters, $\alpha$ and $\beta$, describe the contributions of the CS and US, respectively, to the growth of the association between the CS and US. In the terms of this model, selective associations would be said to occur whenever the rate of growth of a CS-US association can only be characterized by a single parameter, unique to the CS-US combination, that cannot be reduced to separate parameters for CS and US.

The present data demonstrate a stimulus-reinforcer interaction. Strong visual dominance was observed in appetitive Pavlovian conditioning in both the compound-cue and single-cue designs, whereas strong auditory dominance was observed in aversive conditioning in both designs.

The low level of responding in the six groups of Experiment 2 that received independent presentations of a CS and a US (i.e., the zero-contingency control groups) indicates that responding in the experimental groups was conditioned (i.e., reflects associations). Foree and LoLordo (1973, 1975; LoLordo \& Furrow, 1976) used an instrumental procedure in their experiment and did not include groups analogous to the zero-contingency groups of the present experiment. Thus, the present experiment contains the first demonstration that responses to red light paired with food, and to tone paired with electric shock, are associative.

The results of the present experiments are compatible with a selective association account. They are also compatible with several alternative accounts that are associative, but not selective, as the word is used here. Rescorla and Holland (1976) proposed one alternative to selective associative accounts of stimulus-reinforcer interactions like that observed in the present experiments. Applied to the present case, this account asserts that the presentation of food increases attention to visual cues, whereas the presentation of electric shock increases attention to auditory cues. Consequently, the presentation of food should cause visual cues to be more readily associated with any US than are auditory cues. Conversely, the presentation of shock should cause auditory cues to be more readily associated with any US than are visual cues. This attentional account does not require the postulation of specific learning-rate parameters for particular CS-US combinations. This account and a selective association account make differential predictions in an experiment in which one group of pigeons receives pairings of the compound and food, with electric shocks occurring between trials, whereas a second group receives pairings of the same compound and electric shock, with food being presented between trials-but such an experiment has not been conducted (see Rescorla \& Furrow, 1977, for a formally similar experiment using this design).

Another associative account of the present stimulusreinforcer interaction that does not postulate selective associations is based on differential initial responses to the various CSs (see Jacobs \& LoLordo, 1977, 1980; LoLordo, 1979, for a discussion of this issue). Suppose that the tone is initially aversive and the red light is neutral. When the compound is paired with electric shock, the auditory element very quickly attains considerable strength, whereas the visual element acquires relatively little associative strength. According to the Rescorla-Wagner model (1972), once the sum of the associative strengths of the two elements reaches asymptote, there will be no further conditioning to either element. Thus, there would be much more conditioning to the auditory than to the visual element, given our assumption. Mackintosh's (1975) model of overshadowing makes the same prediction. The same assumption predicts visual dominance when the compound is paired with food, if we also assume that an aversive (auditory) stimulus functions like an inhibitor of appetitive conditioning, that is, initially falls below the neutral visual stimulus on a continuum of appetitive associative strength (Dickinson \& Dearing, 1979). This account can explain the data of the compound-cue groups, but incorrectly predicts that conditioning will occur when a red light is repeatedly paired with electric shock, or a tone with food.

Although they rely on different mechanisms, all the accounts suggested thus far have in common the assertion that the stimulus-reinforcer interaction observed in these experiments is the result of the formation of strong associations between tone and electric shock and between red light and food, and of weaker (or no) associations between red light and electric shock and between tone and food. Such an assertion is not required by the data. Perhaps the stimulusreinforcer interaction we have observed results not from associative differences, but from the relative failure of some associations to be manifested in performance (see, e.g., Holland, 1977). In the present case, birds were observed during conditioning; hence, failure to observe a conditioned response in the 
groups that receive tone-food and red light-shock pairings was not due to the failure of a single, designated response to reveal conditioning. Nonetheless, the absence of a conditioned response in this situation may reflect a failure of performance, rather than a failure of association formation.

Holland (1977) has suggested several indirect procedures for assessing associations that are not reflected by performance changes during acquisition (see also Weisman \& Dodd, 1979). Such procedures include transfer of training procedures such as blocking, second-order conditioning, and the demonstration of conditioned reinforcement. In the case of blocking, the relative ability of tone and red light separately paired with food to block conditioning to an added, third stimulus could be assessed. If our stimulusreinforcer interaction reflects selective associative effects, then, when food is the US, red light should be a more effective blocking stimulus than tone. The converse should be true when electric shock is the US.

\section{REFERENCE NOTE}

1. Winokur, S., \& Boe, R. Effects of an auditory CS in automaintenance training with pigeons. Paper presented at the Psychonomic Society meeting, Denver, 1975.

\section{REFERENCES}

Azrin, N. H. A technique for delivering shock to pigeons. Journal of the Experimental Analysis of Behavior, 1959, 2, 161-163.

Cougrilin, R. C., JR. Inexpensive pubis electrodes for delivery of shock to pigeons. Journal of the Experimental Analysis of Behavior, 1970, 13, 368-369.

Dickinson, A., \& Dearing, M. F. Appetitive-aversive interactions and inhibitory processes. In A. Dickinson \& R. A. Boakes (Eds.), Mechanisms of learning and motivation. Hillsdale, N.J: Erlbaum, 1979.

Fartitinc, G. W. Effect of a signal previously paired with free food on operant response rate in pigeons. Psychonomic Science, 1971, 23, 343-344.

Forf, D. D., \& LoLordo, V. M. Attention in the pigeon: The differential effects of food-getting vs. shock avoidance procedures. Journal of Comparative and Physiological Psychology, $1973,85,551-558$.

Forke, D. D., \& LoLordo, V. M. Stimulus-reinforcer interactions in the pigeon: The role of electric shock and the avoidance contingency. Journal of Experimental Psychology: Animal Behavior Processes, 1975, 1, 39-46.

Garcia, J., \& Koflling, R. A. Relation of cue to consequence in avoidance learning. Psychonomic Science, 1966, 4, 123-124.

Holland, P. C. Conditioned stimulus as a determinant of the form of the Pavlovian conditioned response. Journal of Ex- perimental Psychology: Animal Behavior Processes, 1977, 3, 77-104.

J ACors, W. J., \& LoLorno, V. M. The sensory basis of avoidance responding in the rat. Learning and Motivation, 1977, 8, 448-466.

Jacors, W. J., \& LoLondo, V. M. Constraints on Pavlovian aversive conditioning: Implications for avoidance learning in the rat. Learning and Motivation, 1980, 11, 427-455.

L.FYland, C. M., \& Mackintosh, N. J. Blocking of first- and second-order autoshaping in pigeons. Animal learning \& Behavior, 1978, 6, 391-394.

LoLordo, V. M. Selective associations. In A. Dickinson \& R. A. Boakes (Eds.), Mechanisms of learning and motivation. Hillsdale, N.J: Erlbaum, 1979.

LoLorno, V. M., \& Furrow, D. R. Control by the auditory or the visual element of a compound discriminative stimulus: Effects of feedback. Journal of the Experimental Analysis of Behavior, 1976, 25, 251-256.

Mackintosh. N. J. A theory of attention: Variations in the associability of stimuli with reinforcement. Psychological Review, 1975, 82, 276-298.

Niwlin, R. The relation of Pavlovian and autoshaping outcomes. Unpublished doctoral dissertation, University of North Carolina, Chapel Hill, 1974.

Rashotte, M. E., Griffin, R. W., \& Sisk, C. I. Secondorder conditioning of the pigeon's keypeck. Animal Learning \& Behavior, 1977, 5, 25-38.

Rescorla, R, A., \& Furrow, D. R. Stimulus similarity as a determinant of Pavlovian conditioning. Journal of Experimental Psychology: Animal Behavior Processes, 1977, 3, 203-215.

Rescorta, R. A., \& Hol.tand, P. C. Some behavioral approaches to the study of learning. In M. R. Rosenzweig \& E. L. Bennett (Eds.), Neural mechanisms of learning and memory. Cambridge, Mass: M.I.T. Press, 1976.

Rescorla, R. A., \& Wagner, A. R. A theory of Pavlovian conditioning: Variations in the effectiveness of reinforcement and non-reinforcement. In A. H. Black \& W. F. Prokasy (Eds.), Classical conditioning II: Current research and theory. New York: Appleton-Century-Crofts, 1972.

Schwartz, B. On going back to nature: A review of Seligman and Hager's Biological boundaries of learning. Journal of the Experimental Analysis of Behavior, 1974, 21, 183-198.

Sutherland, N. S., \& Mackintosh, N. J. Mechanisms of animal discrimination learning. New York: Academic Press, 1971.

TоміЕ, A. Effects of unpredictable food upon the subsequent acquisition of autoshaping: Analysis of the context blocking hypothesis. In C. M. Locurto, H. S. Terrace, \& J. Gibbon (Eds.), Autoshaping and conditioning theory. New York: Academic Press, 1980.

Wasserman, E. A. Auto-shaping: The selection and direction of behavior by predictive stimuli. Unpublished doctoral dissertation, Indiana University, 1972.

Weisman, R. G., \& DoDd, P. W. D. The study of association: Methodology and basic phenomena. In A. Dickinson \& R. A. Boakes (Eds.), Mechanisms of learning and motivation. Hillsdale, N.J: Erlbaum, 1979.

(Received for publication February 25, 1980; revision accepted June 20,1980 .) 